\section{Briginal aldicleł.}

\section{INSOLATION.1}

BY HKNRY JACKsoN, M.D. Assistant Visiting Physician of the Boston City Hospital.

During the heated term of last August it was my good fortune to have under my care at the City Hospital several cases of insolation; as they offered many points of interest to me, I feel that a short discussion of the subject way not be out of place in this Section.

The common terms "sunstroke" and "insolation" (derived from the verb "insolate," meaning to expose to the rays of the suin) are not wholly appropriate, as mauy cases of the most severe formo of this disease are developed in persons exposed to great heat in attics or overheuted rooms, though entirely shielded from the direct rays of the sun. 'The term "thermic fever," though etiologically more comprehensive, is not in common use in our city, and l therefore choose the word "insolation" as the title of my paper.

As the result of exposure to severe heat, we may havo two different diseases produced, namely, heat exhaustion and thermic fever.

The cases of slight prostration, headache and mulaise produced by hent may be classified as the mildest types of heat exhaustion. During the hot week many persons that had been overcome by heat were brought to the hospital in the police ambulance; yet they were perfectly conscious, had a normal temperature, and after a short period of rest were allowed to go howe, as their symptoms were not sufficiently severe to warraut their admission considering the overcrowded condition of the hospital. Several cases were admitted that were unable to leave the hospital on account of severe headache, dizziness and exhaustion, though when they reached the hospital, at all events, their temperature was not elevated.

As the result of exposure to heat, profound collapse, with loss of consciousuess and reluxation of the whole muscular system, may be seen. In such cases the temperature is subnormal and the pulse rapid. The condition is comparable to profound collapse as seen in serious surgical accidents. I have not had any experience with cases of this form, though Dr. 11. C. Wood speaks of this form of heat exhaustion as not uncommon in Philadelphia. 'The treatment suitable for cases of collapse from exposure to heat is the same as that for collapse-from any other cause, namely, vigorous stimulation and the application of heat externally.

A third form of disease, the result of exposure to great heat is described, namely, a continued fever which may simulate typhoid fever. Dr. Guiteras has especially culled attention to this disease, aud expressed the opinion that wany cases of so-called typhoid fever in Florida are really cases of insolation of this type. $I$ report to-night one case of continued fever that $I$ believe was due to the results of long exposure to great heat.

In summary, then, we may say that, as a result of exposure to excessive heat, we may have four distinct distased conditions :

(1) Exhaustion, with normal temperature.

(2) Collapse, with subnormal temperature. toms.

(y) Intense fever combined with furious acute symp-

2 Read before the Clinioal Seotion of the Sufiolk Distrlot Medioa Soolety, November 18, 1898.
(4) A continued fever with symptoms suggesting a continued fever similar to typhoid.

In 1895 Dr. C. I. Withington published a valuable paper on "Heat Prostration" in the sixth series of the Medical and Surgical Reports of the Boston City Hospital. In this paper he analyzed one hundred cases. 'Two-thirds were the result of exposure to the direct rays of the sun, and one-third to exposure to indirect heut. In the latter class were included workers in sugar refineries, iron foundries. bake-shops, furuacerooms and stables. Of the $100 \mathrm{cases}, 28$ died and 72 recovered. In this series the highost recorded temperature was $111.5^{\circ}$, and the highest temperature with recovery $109.5^{\circ}$. In 84 cases there was loss of cousciousness, and convulsions in 30 . Dr. Withington noted that the pupils did not respond to light and were usually contracted, though at times dilated. 'This accords with the statements usually found in the text-books, though in all my severe cases, with a single exception, the pupils were contracted to a pin-point size. A secondary rise of temperuture after the fever had been reduced by cold was not unusual. Of great practical importance is the fact that in the cold bath there may be a fall of temperature to a point fur below normal, accompanied by symptoms of serious collapse. Therefore in using a bath the rectal temperature must be taken frequently; and when the thermometer registers $102^{\circ}$ the patient should bo removed from the bath, as the temperature usually continues to fall after the patient has been returned to his bed. In six autopsies quoted by Dr. Withington the chief pathological lesions were sub-endocardial and pulmonary hemorrhages, hyperemia and edema of the meninges, and a flucl condition of the blood as a whole.

'Through the kindness of my colleague, Dr. Sears, I am able to report 22 cases that entered our two services: 18 men, three women, and one boy of fifteen years.

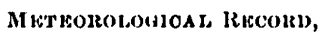

Accorling to observatious furnishod by Sorgeant J. W. Smith, of tho United States signa) Corp's, A ugust b-13, inclusivo:

\begin{tabular}{|c|c|c|c|c|c|c|c|c|c|}
\hline Jato. & Cuses & 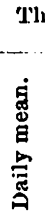 & 昜 & 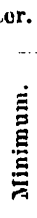 & Rolnt & $\begin{array}{l}\dot{H} \\
\dot{0} \\
\dot{\delta} \\
\dot{\alpha}\end{array}$ & 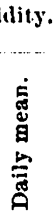 & Won & 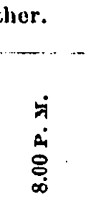 \\
\hline '1'....6 & & (25 & 60 & 65 & 81 & 96 & 94 & Cloudy. & Cloudy. \\
\hline T....? & & i & (M) & 61 & 95 & $7 t$ & 84 & Clouily. & Cloar. \\
\hline S...8 & & 75 & 80 & 61 & 96 & 76 & 86 & Clear. & Clear. \\
\hline s....s & & 82 & 92 & 72 & (bx & 70 & 74 & Frir. & Clear. \\
\hline M..10 & 2 & 86 & 95 & 76 & 70 & 70 & 70 & Cloudy. & Clear. \\
\hline T...11 & 5 & 82 & 89 & 76 & 62 & 64 & 63 & Clear. & Clear. \\
\hline W..12 & 12 & 82 & 80 & 76 & 68 & 71 & 70 & Clenr. & Cloar. \\
\hline 'T...13 & 2 & 70 & 81 & 70 & 74 & 78 & 76 & Fuir. & Fair. \\
\hline
\end{tabular}

One case entered some time after the heated term had passed by, the case of continued fever.

Eleven of the cuses were mild; 10 were severe, with hyperpyrexia; and one was the case that I have mentioned as belonging to the type of coninued fever due to heat. Seventeen of the cases were the result of direct exposure to the rays of the sun, and tive were prostrated by indirect beat. Of the latter, three 
were laundresses, one a baker and ove a stablemau who was working in the loft of a stable on Portland Street. Two of the severe cases suffered from indirect heat.

Five of the 22 cases died, namely, 50 per cent. of the cases severe enough to warrant one to make an unfavorable proguosis, 11 of the cases being evidently of a mild type.

'Two of the cases entered on the fourth day of the heated period, five on the fifth and 12 on the sixth day ; two were entered on the morning of the seventh pu day, but properly they should etiologically be entered as belonging to the sixth day, as they were both night-workers and were brought in in the early morning, after the temperature had heen already lowered by a fresh east wind.

It is evident from this list that the ultimate cause of the prostration is to be found rather in prolonged heat than in the excessive heat of a single day. Most of the cases entered two days after the acme had been reached. These data are in accord with our practical experience that sunstrokes are not usual as the result of one or two days of excessive heat such as usually occur every summer.

During this period the humidity was not high and the weather was clear; the same may be said in a genoral way of Dr. Withington's series of cases. 'They did not occur in weather with a-relatively high bumidity. In Germany where sunstroke is rare amongst civilians, soldiers are not infrequently overcome by the heat during forced marches, or in military manœuvres during hot, moist weather when the soldiers are burdened by heavy clothes and knapsacks. I remember Kussmaul said that he hai not seen sunstroke except under such conditions.

The cases which I have to report I divide as fullows: Mild, eleven cases, five without fever and six with low temperature; ten severe cases, with hyper. pyrexia; one case continued fever.

\section{FIVE CASES WITHOUT YEVER.}

One of these cases was unconscious on entrance, two were conscious though dazed, one complained of severe headache and dizziness, and one was simply exhausted. In uone of the cases were the pupily contracted, nor was there in any of them any loss of pupil reflex. One of the cases complained of abdominal pain, and had cramps in the hands. In all, the conjunctiva were congested. In four of the cases where a history was obtained prodromal symptoms of lassitude, prostration, beadache, and, in two iustances, fainting, had preceded the extreme depression which caused their removal to the hospital. In only one cuse was there a distinct history of a cessation of sweating before the onset of more unfavorable symptoms. One had worked in a bake-shop on the last hot night of the series, and fuinted twice before he was brought to the hospital with a normal temperature, though no baths had been given outside of the hospital. well.

Ail left the hospital in two or three days apparently

$$
\text { SIX CASES OF MODERATE FEVER. }
$$

Four of these cases were perfectly unconscious on entrance; while two were semi-conscious, though much duzed and roused only with difficulty. In five of the cases the pupils were equal and reacted perfectly; in one the pupils were contracted. In all the coujunctivæ were injected. Prodromata were more marked than in the preceding series. One had complained of vomiting and marked prostration for two days before the onset of unconsciousness; three had severe headache and general malaise; again, one only noted and spoke of a cessation of sweating. The range of temperature was from $100^{\circ} 10104^{\circ}$; in all there was a slight elevation of temperature on the second day, the temperature being normal on and after the third day. In the case with contracted pupils there.was retraction of the head, and an occasional convulsion of the whole body. In the other cases no untoward symptoms were noted except moderate headuche and weakness. The only treatment employed was sponging with cold water.

All were discharged on the second or third day after defervescence. 'Two were lauudresses; the others worked out of doors.

\section{TEN SEVKRE CASES.}

One case entered moribund, death taking place in the bath given shortly after entrance; of this case I can only report that the temperature was $111^{\circ}$ in the rectum. In the other nine cases the following symptoms were noted: In all there was profound unconsciousness, with stertorous respiration. In all there was marked rigidity of the whole body and the extremities were extended with difficulty, becoming im. mediately flexed when not forcibly held. In all the pupils were contracted to a pin-point in size, and did not react to light or other stimulus; the conjunctiva were deeply injected, and in two cases the eyes were rotated sharply upwards. In eight cases there were general convulsions, frequently recurring. Profuse, involuntary dejections and vomiting were seen in five cases, and noted as absent in two. Albuminuria and ciasts were found in three cases, and noted as ubsent in only one instance. In all the cases the pulse was rapid and poor, being several times imperceptible at the wrist. Rales were heard throughout the chest in each case examined. I give the range of temperature with the result in each cate:

$106^{\circ}$
$105^{\circ}:$
$108^{\circ}$
$110^{\circ}:$
$110^{\circ}:$
$110^{\circ}:$
$111^{\circ}:$
$102^{\circ}:$
$109^{\circ}$
$109.5^{\circ}$

Death, 7th day, faundice and puoumonia. Death in a few hours.

Recovered.

Denth, 14th diny, odema of pin.

Recovered.

Death in four hours.

lintered moribund.

Recovered (lce-l)ath at station-houge).

Recovored.

Recovered.

Cask 1. Temperature $106^{\circ}$. Baker. Sintered on eve. ning of August 10th. 'Temperature fell rapidly after icewater baths, and toward norning he was semi-conscious. During the next few days juundice developed, and he was delirious. The liver was enlarged. August 16th, consolidation of the lower lobe of the left lung, and death the next day.

CABE II. 'lemperature $105^{\circ}$. Was put in a cold bath, and removed when the temperature was $101^{\circ}$. He was wrapped in blankets, rubbed vigorously, and stimulated; but he failed to respond. 'The temperature fell to $93.6^{\circ}$, and he died in a few hours.

Cask 1II. Temperature $108^{\circ}$. Temperature soon fell under use of ice-cold packs, and in a few hours he was conscious. No untoward symptoms. Eloped on fourth day.

Cask IV. Tempernture $110^{\circ}$. Boy of fifteen. Mentally deficient, and a resident of an institution. Profuse vomiting and involuntary dejections. 'lemperature fell rapidly under ice-cold sponging and packs. He never recovered consciousness. 'There was marked rigidity of 
the neck, trunk and extremities : constant vigilance and occasional twitchings of face and legs. Death on the fourteenth dav. Autopsy : Much edema of the pia. When the calvarium was removed the brain looked as if covered with a thick layer of wine jelly.

CAś V. Temperature $110^{\circ}$. Temperature fell quickly to $102^{\circ}$ under ice.cold packs and sponging. He was then wrapped in blankets and rubbed vigorously. 'The temper. ature fell further to $99^{\circ}$, but rose agnin to $103^{\circ}$ in the evening. There were several severe convulsions. There was moderate fever for several days, but no further untoward symptoms.

Casv VI. $110^{\circ}$. Death in four hours. Convulsions.

Casi: VII. $111^{\circ}$. Moribund.

Case VIII. $102^{\circ}$. Ice bath at the station. Convulsions, otherwise quick and uninterrupted recovery.

Case IX. 'Temperature $109^{\circ}$. Was left in cold bath until the temperature reached normal. On removal the temperature continued to fall, reaching $93.6^{\circ}$. During the next two weeks the man was very weak, delirious at times, and the temperature normal or subnormal. On $\Lambda$ ugust 26 th he was unable to walk alone, and the gait was ataxic; the muscles were flabby, knee-jerks present. Through September he was confined to the bed, but gradually recovered his strength and on October 8 th he could walk alone.

Cast X. Temperature $109.5^{\circ}$. Was placed in an ice bath and kept there until the temperature reached $102.5^{\circ}$. After removal the temperature fell lower, to $98.6^{\circ}$. During the evening there were convulsions and a secondary rise of temperature to $107^{\circ}$. He was conscious the next morning; and except for a moderate fever for four days no other symptoms developed.

All of the cases were treated by external application of ice-water, some by full baths and others by pouring cold water over the body as they lay on rubber sheets in bed. In all cuses the importance of stopping the application of cold by the time the temperature reached in the rectum $102^{\circ}$ was fully emphasized. In those cases that I watched personally I felt that the cold baths were much more efficacious when the superficial circulation was stimulated by the alternate use of vigorous friction and wrapping the patients in woolen blankets for short periods. In addition to the application of cold, the patients were stimulated by the subcutaneous use of brandy and sulphate of strychuia. Sulphate of morphia apparently had a beneficial effect in controlling the convulsions.

The clinical phenomena of severe cuses of suustroke all point to a direct and profound disturbance of the nervous system - coma, contracted pupils, convulsions-all symptoms suggesting some direct effect upon the brain as a whole, rather than discrete focal lesions. In Case IV, the boy, the clinical symptoms strongly suguested some pathological process in the meninges, and the autopsy confirmed the clinical diagnosis, showing that the disturbing factor was an extensive edema of the pia.

'Two main theories may be advanced in explanation of the nervous phenomena which follow severe sunstroke; they may be the direct result of pathological changes produced in the brain and meninges, or they may be dependent upon the poisonous action of some toxine set free in the body as the result of the disturbance of the heat equilibrium. I have been unable to find many reports of the post-mortem appearances found after sunstroke, but such as I have found sug. gest that we may find suflicient cause for the clinical symptoms in the lesions of the brain and meninges.

\section{ONE CASE OF CONTINUED FEVER.}

Woman, age twenty-four. Entered my wards Angust 26th. No items of importance in her family or previous history. On one of the hottest days of the hot period she went in bathing at South Boston Point and stayed four hours in the water. Her head was not protected, and she says she did not wet her hair. Severe headache followed. Five days later a doctor was called who found her temperature $103.8^{\circ}$. She became delirious; had severe herdache and backache; pupils regular and small. The pulse was occasionally irregular. The temperature continued, but gradually fell, reaching almost the normal point when she entered the hospital. She entered the hospital, as she was much annoyed by any noise. Typhoid fever was considered, also meningitis, which was suggested by the intense headache and the focal signs in the pupils.

I found the following condition: Herpetic eruption on the lips (rarely if ever seen in typhoid). No enlargement of the spleen. Abdomen negative. Urine negative. She had much headache and seemed weak. After entrance to the hospital there was no fever, and she gradually improved without the occurrence of unfavorable symptoins.

Before she entered the hospital she had symptoms evidently pointing to meningitis, according to the account given me by the doctor who saw her in consultation. I believe that those symptoms were the result of lesions produced by suustroke.

\section{THE 'TEACHING OF CLIMATOLOCY IN MEDI- CAL SCHOOLS.}

BY ROHERT IN (, WARD, BOSTON, Instructor in Climatoloyy in Harvard University.

'Ine time has come when climatology should be generally taught in our medical schools. It is a sub. ject of great importance to medical men, and one about which they should all have some rational information. In the hope of arousing the interest of the medical profession and perhaps also of provoking further discussion of the subject, the present paper is herewith presented.

The intimate relations existing between atmospheric conditions and health have been the theme of comment and investigation from the days of the earliest writings on medicine and on meteorology down to the present time. From the statement made by Hippocrates over two thousand years ago, that "Whoever wishes to study the healing art properly must do this - first, he must attentively consider the seasons of the year," down to the most recent articles in the last numbers of our medical journals, there will be found abundant proof that medical men have been and are fully alive to the important influences which climatic conditions loave on disease. The last few years, especially, have witnessed a remarkable increase of interest in this meteorologic or climatic side of medicine, both on the part of medical men thenselves and on the part of metenrologists also. The present activity along these lines seems to bo largely, if not wholly, due to the fact that meteorology is itself so young a science that it has not been able, until recently, to offer as its contribution to medical or sanitary climatology anything like systematic and reliable 